\title{
Serum interferon-gamma (IFN- $\gamma$ ) and expression profile of IFN- $\gamma$ provide diagnostic signatures of unexplained infertility in females with Hashimoto's Thyroiditis.
}

\author{
Nearmeen Rashad ${ }^{1}$, Reham El Shabrawy ${ }^{1}$, Ahmed Radwan ${ }^{1}$, Reem Allam ${ }^{1}$, Rehab \\ Abdul-Maksoud ${ }^{1}$, and Magda Sherif ${ }^{1}$ \\ ${ }^{1}$ Zagazig University Faculty of Human Medicine
}

July 22, 2020

\begin{abstract}
Hashimoto's thyroiditis (HT) is a T cell-mediated autoimmune disease. Interferon-gamma (IFN- $\gamma$ ) is a crucial cytokine that plays a crucial role and shows increased level in HT. Unexplained infertility (UEI) is a condition in which no cause has been found to explain the failure of conception. We aimed in this study to detect the frequency of HT patients that suffer from UEI in a sample of Egyptian women. Also, to assess the serum interferon-gamma (IFN- $\gamma$ ) level and expression levels of IFN- $\gamma$ gene in this group of patients to find out the possibility of using them as diagnostic markers for UEI in patients with HT. This cross-sectional study included 120 women with HT. We assessed fertility in both groups in which female patients with UEI were detected. For all patients, HT was diagnosed based on clinical and laboratory measures, serum IFN- $\gamma$ was measured using enzyme-linked immunosorbent assay and FN- $\gamma$ mRNA expression was analyzed using real-time polymerase chain reaction. Our results revealed that $37.5 \%$ of studied Egyptian women with HT had UEI. There was a significant positive correlation between serum IFN- $\gamma$ and IFN $\gamma$ gene expression with thyroid auto-antibodies as well as TSH, while there was a negative correlation with FT3, FT4, and AMH. Interestingly, among studied parameters, TSH and FT3 were the only variables independently associated with serum IFN- $\gamma$ while FT3 was only variables independently associated with IFN- $\gamma$ gene expression by linear regression analysis.
\end{abstract}

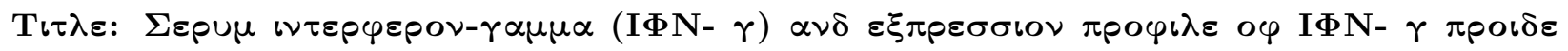

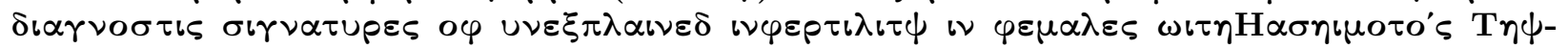

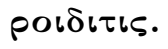

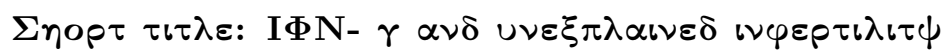

Nearmeen M. Rashad*1, Reham M. El Shabrawy², Ahmed M. Radwan ${ }^{3}$, Reem M. Allam ${ }^{4}$, Rehab S. Abdul-Maksoud $^{5}$, Magda. M. Sherif ${ }^{1}$

${ }^{1}$ Internal Medicine Department, Faculty of Medicine, Zagazig University, Egypt.

${ }^{2}$ Medical Microbiology \& Immunology Department, Faculty of Medicine, Zagazig University, Egypt.

${ }^{3}$ Obstetrics and Gynecology Department, Faculty of Medicine, Zagazig University, Zagazig, Egypt.

${ }^{4}$ Clinical Pathology Department, Faculty of Medicine, Zagazig University, Egypt.

${ }^{5}$ Medical Biochemistry Department, Faculty of Medicine, Zagazig University, Zagazig, Egypt.

* Corresponding author: Nearmeen M. Rashad

Tel.: +201224248642 
E-mail address:

Nearmeen M. Rashad:nrashad78@yahoo.com \&n.rashad@zu.edu.eg.

Reham M El Shabrawy: reham_elshabrawy@yahoo.com \& reham.elshabrawy@zu.edu.eg.

Ahmed M. Radwan: yasm.79@hotmail.com

Magda. M. Sherif: MagyAKM2000@yahoo.com

Reem M. Allam: reem.allam@ymail.com

\section{Abbreviations}

Tabs: thyroid autoantibodies

HT: Hashimoto's thyroiditis

FT4: free T4

FT3: free T3

TSH: thyrotrophin

TPO: thyroid peroxidase

Tg: thyroglobulin

UEI: Unexplained infertility

AMH: Anti-Müllerian hormone

TVS: transvaginal ultrasound

AFC: antral follicular count (AFC)

RT-PCR: Quantitative real-time polymerase chain reaction

ROC: Receiver operating characteristic

Authors' contributions: NMR, RMS, AMR, MMS, RMA conceived of the presented idea, collected patients' samples and clinical data, developed the theory, performed the computations, verified the analytical methods and contributed to the final manuscript. RMS, RMA prepared sample for laboratory investigations. NMR, RMA wrote the paper. Statistical analysis, interpretation of data and preparation NMR, RMA did the paper for submitting international. All of the authors performed critical revision of the manuscript. All authors have read and approved the manuscript.

\section{Summary}

Hashimoto's thyroiditis (HT) is a T cell-mediated autoimmune disease. Interferon-gamma (IFN- $\gamma$ ) is a crucial cytokine that plays a crucial role and shows increased level in HT. Unexplained infertility (UEI) is a condition in which no cause has been found to explain the failure of conception. We aimed in this study to detect the frequency of HT patients that suffer from UEI in a sample of Egyptian women. Also, to assess the serum interferon-gamma (IFN- $\gamma$ ) level and expression levels of IFN- $\gamma$ gene in this group of patients to find out the possibility of using them as diagnostic markers for UEI in patients with HT. This cross-sectional study included 120 women with HT. We assessed fertility in both groups in which female patients with UEI were detected. For all patients, HT was diagnosed based on clinical and laboratory measures, serum IFN- $\gamma$ was measured using enzyme-linked immunosorbent assay and FN- $\gamma$ mRNA expression was analyzed using real-time polymerase chain reaction. Our results revealed that $37.5 \%$ of studied Egyptian women with HT had UEI. There was a significant positive correlation between serum IFN- $\gamma$ and IFN- $\gamma$ gene expression with thyroid auto-antibodies as well as TSH, while there was a negative correlation with FT3, FT4, and AMH. Interestingly, among studied parameters, TSH and FT3 were the only variables independently associated 
with serum IFN- $\gamma$ while FT3 was only variables independently associated with IFN- $\gamma$ gene expression by linear regression analysis.

Conclusions : $37.5 \%$ of the studied Egyptian women with HT had UEI there were statistically significant increases of the age of menarche, TSH, anti-TPO, anti-TG, serum IFN- $\gamma$, IFN- $\gamma$ mRNA in UEI group as compared to the fertile group. Cutoff values of $16.7 \mathrm{pg} / \mathrm{dl}$ for IFN- $\gamma$ and $2.65 \mathrm{pg} / \mathrm{dl}$ for IFN- $\gamma$ gene expression are specific and sensitive for differentiating UEI from fertile women.

Keywords : Hashimoto's thyroiditis; UEI; Serum IFN- $\gamma$ · IFN- $\gamma$ gene expression; TPO- Ab.

\section{Introduction}

Infertility is defined as the failure to conceive after one year of unprotected intercourse. Approximately $7 \%-15 \%$ of couples of reproductive age suffer from infertility. Many factors, including endocrine and immunological factors, might predispose a couple to infertility [1]. Unexplained infertility (UEI) is a frustrating state for the subfertile couple with unknown causes. UEI is a diagnosis of exclusion when the necessary infertility workup is found to be normal [2]. Involvement of the immune system in unexplained infertility has been found [1].

It is known that the induction of immunologic tolerance in the decidua is vital to accept fetal alloantigens. Cytokines play an important role in establishing and maintenance of such tolerance. Th1 cytokines (like IFN- $\gamma$, IL-2, and TNF) cause pregnancy failure, whereas Th2 cytokines (like IL-4, IL-5 and IL-10, which suppress Th1 responses) cause the tolerance to the fetus and pregnancy. Imbalance of the cytokine network can lead to impaired pregnancy and infertility, including unexplained infertility [3].

Published studies highlighted that reduced fertility might be associated with the dysregulation of immune system reactions resulting in autoimmunity $[4,5]$. One of the most common autoimmune diseases that affect females in the reproductive age is Hashimoto thyroiditis [6].

Hashimoto's thyroiditis (HT) is an autoimmune thyroid disease characterized by follicular lymphocytic infiltration in the thyroid gland with the formation of germinal centres, atrophy of the follicular epithelial cells, Hurthle cell change, and gradual fibrous replacement of the thyroid parenchyma [7]. Disturbed balance of pro- and anti-inflammatory cytokines are thought to play an essential role in the pathogenesis of autoimmune thyroid diseases. Correlation between a high level of Interferon (IFN)- $\gamma$ and autoimmune thyroiditis has been widely established [8].

Therefore, we aimed to evaluate serum IFN- $\gamma$ level and the level of expression of IFN- $\gamma$ gene in Egyptian women with HT and their possible associations with UEI. Accordingly, we can use IFN- $\gamma$ level and the level of expression of IFN- $\gamma$ gene as an Immunological marker for UEI in female patients suffering from HT.

\section{Methods}

This cross-sectional study included 120 women with HT. Women with HT were divided into two groups, fertile women $(n=75)$, and women with unexplained infertility $(n=45)$. Patients were recruited from outpatient clinics of the Endocrinology Unit of Internal Medicine and Obstetrics and Gynecology Departments, Faculty of Medicine, Zagazig University, Egypt. Diagnosis HT was obtained based on clinical findings, positive serum antibodies; TPO Ab and/or Tg Ab.

Inclusion Criteria: Adult females suffer from both HT and UEI

1. Diagnosis of HT: All participants underwent complete history taking, thorough clinical examination, full clinical assessment and anthropometric measures. Thyroid function tests assessed thyroid dysfunction.

2. Diagnosis of UEI: Infertility is customarily defined as the inability to conceive after 1 year of regular unprotected intercourse. The infertility evaluation is typically initiated after 1 year of trying to conceive, but in couples with advanced female age ( $>35$ years), most practitioners initiate diagnostic 
evaluation after an inability to conceive for 6 months. The Practice Committee of the American Society for Reproductive Medicine (ASRM) published guidelines for a necessary infertility evaluation; It includes a semen analysis, assessment of ovulation, a hysterosalpingogram, tests for ovarian reserve and laparoscopy. If the results of a standard infertility evaluation are normal, a diagnosis of unexplained infertility is made. Ovarian volume and antral follicular count (AFC) were evaluated by transvaginal ultrasound (TVS) [9].

Exclusion criteria for all women included a history of hyperandrogenic states (such as non-classical congenital adrenal hyperplasia, androgen-secreting tumors, Cushing's syndrome, or 21-hydroxylase deficiency), hypertension, liver or kidney diseases. Also, we excluded patients with a history of myocardial infarction, angina, stroke, pregnancy, and diabetes.

\subsection{Blood sampling and testing}

Blood samples were between days 3 and 6 of the menstrual cycle and after an overnight fast and divided into 2 portions: $1 \mathrm{ml}$ of whole blood was collected into EDTA tubes, for RNA extraction. The remaining 4 $\mathrm{ml}$ were collected into plain evacuated tubes for sera separation. Sera were stored at $-20^{\circ} \mathrm{C}$ until analysis.

\subsection{Assay of thyroid function and autoantibody levels}

Electrochemiluminescence measured the serum concentration of free T4 (FT4), free T3 (FT3) and thyrotrophin (TSH) on Cobas 6000 analyzer (ROCHE DIAGNOSTICS).

\subsection{Assay of thyroid autoantibody levels}

Serum anti-TPO using Accu-Bind ELISA kit (Monobind Inc., Lake Forest, CA 92630, USA) and serum anti-TG using Accu-Bind ELISA kit (Monobind Inc., Lake Forest, CA 92630, USA).

\subsection{Hormonal assay of gonadal function}

Estradiol, Progesterone, Testosterone, Follicular stimulating hormone (FSH), Luteinizing Hormone (LH), Prolactine and Anti- Mullerian Hormone (AMH) were measured by Electrochmeiluminescence on Cobas 6000 analyzer (ROCHE DIAGNOSTICS).

\subsection{Serum I $\Phi N-\gamma \lambda \varepsilon \varepsilon \lambda \alpha \sigma \sigma \alpha \psi$}

Was measured using Accu-Bind ELISA kit (Monobind Inc., Lake Forest, CA 92630, USA).

\subsection{I $\Phi N-\gamma \gamma \varepsilon \nu \varepsilon \varepsilon \xi \pi \rho \varepsilon \sigma \sigma \iota \nu$}

\section{RNA isolation, cDNA preparation.}

Total RNA Purification kit (Jena Bioscience, Germany) was used to extract total RNA from EDTA peripheral blood samples after the manufacturer's protocol. The reverse transcription process was done by the SCRIPT Reverse Transcriptase kit (Jena Bioscience, Germany) producing the first-strand cDNA using Oligo (dT) primer and M-MLV RT enzyme. In ice, we mix $1.5 \mu \mathrm{l}$ RNase-free water, $10 \mu \mathrm{l}$ RNA template and $1 \mu \mathrm{l}$ Oligo(dT) primer together, then $4 \mu \mathrm{l} \mathrm{SCRIPT} \mathrm{RT} \mathrm{buffer,} 1 \mu \mathrm{l}$ dNTP Mix, $1 \mu$ l RNase inhibitor, $1 \mu$ l Dithiothreitol stock solution and $0.5 \mu \mathrm{l} \mathrm{SCRIPT}$ reverse transcriptase were added then incubated at $30^{\circ} \mathrm{C}$ for 10 min and $50^{\circ} \mathrm{C}$ for $60 \mathrm{~min}$. The cDNA was stored at $-20^{\circ} \mathrm{C}$ until analysis.

\section{Quantitative real-time polymerase chain reaction (RT-PCR).}

Quantitative real-time RT-PCR for IFN- $\gamma$ gene was performed on a Stratagene Mx3005P qPCR System (Agilent Technologies, Germany) using the qPCR Green Master (Jena Bioscience, Germany). PCR reaction with $20 \mu \mathrm{l}$ final volume was prepared by adding $10 \mu \mathrm{l}$ qPCR Green Master, $0.5 \mu$ l forward primer $(10 \mu \mathrm{M})$, $0.5 \mu \mathrm{l}$ reverse primer $(10 \mu \mathrm{M})$ (Table I), $5 \mu \mathrm{l}$ template cDNA and $4 \mu \mathrm{l} \mathrm{PCR}$ grade water into real time PCR wells. The cycling program was prepared as following $95^{\circ} \mathrm{C}$ for $10 \mathrm{~min}$, then 40 cycles $\left(95^{\circ} \mathrm{C}\right.$ for 15 secs, $58^{\circ} \mathrm{C}$ for $\left.1 \mathrm{~min}\right)$. The transcription levels of target genes were normalized to those of the $\beta$-actin gene, which used as the reference gene. The normalized quantity of the target gene was obtained by subtracting the 
cycle threshold (CT) for $\beta$-actin from the $\mathrm{CT}$ for the target gene ( $\Delta \mathrm{CT}$ sample). The same calculation was performed with controls ( $\Delta \mathrm{CT}$ control). Then $\Delta \Delta \mathrm{CT}$ was calculated as the difference of these values $(\Delta \Delta \mathrm{CT}=\Delta \mathrm{CT}$ sample $-\Delta \mathrm{CT}$ control). Finally, the relative expression was expressed as fold change by a $2-\Delta \Delta \mathrm{CT}$ relative to control.

Table I: Primer used for Quantitative real-time RT-PCR for IFN- $\gamma$ gene.

\begin{tabular}{lll}
\hline & Forward primer & Reverse primer \\
\hline $\mathbf{I \Phi N -} \boldsymbol{\gamma} \boldsymbol{\gamma} \boldsymbol{\Sigma} \boldsymbol{\varepsilon}$ & 5' -GCATCCAAAAGAGTGTGGAG-3' & 5' -GACAGTTCAGCCATCACTTGG-3' \\
$\beta$-actin & 5'-TTG CCG ACA GGA TGC AGA A-3' & 5'-GCC GAT CCA CAC GGAGTA CT-3' \\
\hline
\end{tabular}

\subsection{Statistical Analysis}

Statistical analyses were performed using the Statistical Package for the Social Sciences for Windows (version 21.0; SPSS, Chicago, IL, USA).

\section{Results}

\subsection{Clinical and laboratory characteristics in HT patients.}

This cross-sectional study included 120 women with HT among the studied cases, 75 women were fertile, and 45 women had UEI, there were statistically significant increases of the age of menarche, TSH, anti-TPO, anti-TG, serum IFN- $\gamma$, IFN- $\gamma$ mRNA, in UEI group as compared to fertile group $(\mathrm{P}<0.05)$. On the other hand, there were significantly lower values of AMH as AFC compared to the fertile group $(\mathrm{P}<0.05)$. (Table $1)$.

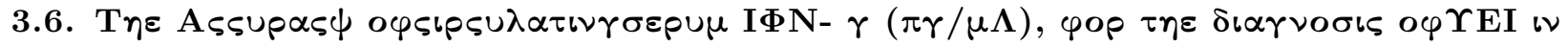
$\pi \alpha \tau \iota \varepsilon \nu \tau \varsigma$ o $\mathrm{HT} \beta \psi \mathrm{PO}^{\prime \prime} \alpha \nu \alpha \lambda \psi \sigma \iota \varsigma$

Regarding its power in differentiating fertile women from women with UEI, the AUC was 0.984 (95\% CI = $0.957-1.000)$ with sensitivity $=99.6 \%$, specificity $=96 \%$, and the cutoff values $(16.7 \mathrm{pg} / \mathrm{mL})$, (Figure 1$)$.

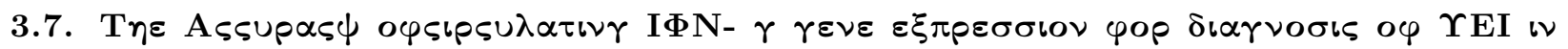

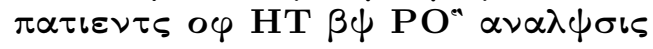

Regarding the power in differentiating fertile women from women with UEF. The AUC was 0.912 (95\% CI $=0.860-0.965)$ with sensitivity $=90.4 \%$, specificity $=94.2 \%$, and the cutoff values $(2.65)$, (Figure 2).

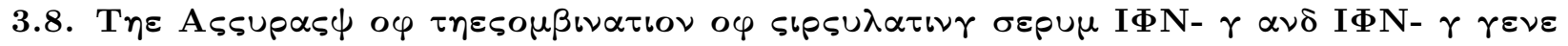

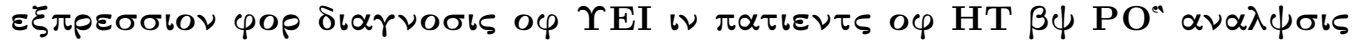

Regarding the power in differentiating fertile women from women with UEF. The AUC was 0.953 (95\% CI $=0.889-1.000)$ with sensitivity $=90.4 \%$, specificity $=94.2 \%,($ Figure 3$)$.

\section{Discussion}

The WHO worldwide estimation suggests that infertility currently affects up to 50-80 million women, with a variable incidence that may rise to about $50 \%$ of all women [10]. Infertility in women can occur due to several factors that include ovulatory dysfunction, tubal, cervical and/or uterine factors, as well as endometriosis. However, in $20-30 \%$ of cases, infertility remains unexplained [10].

Gathering studies have reported that increased expression of IFN- $\gamma$ results in cell-mediated immune destruction of many organs which in turn leads to activation of humoral immune response and increase cytokine production and this leads to initiation or progression of autoimmune disease. Increased levels of IFN- $\gamma$ have been strongly linked to HT [11]. 
Interesting, this cross-sectional study shows that about $37.5 \%$ of studied women with HT had UEI, which is associated with idiopathic poor ovarian reserve as detected by low values of AFC count and AMH in patients suffer from UIE.

Thyroid hormones seem to participate in the complex regulation of ovarian function [6]. According to our results, females with UEI had statistically significant increases in the age of menarche and TSH as compared to the fertile group. Other studies had shown the influence of TSH on fertility. Jokar et al., had investigated the relationship between TSH and conception rates and have shown that women with UEI have significantly higher TSH levels than normal fertile women [12]. High level of TSH in UEI was also concluded by other studies $[13,14]$.

Thyroid autoantibodies play an essential role in the immunopathogenic process of autoimmune thyroiditis. Increased levels of TPO-abs is considered the most sensitive marker of autoimmune disease [15]. In this study, women with UEI showed statistically significant increases of anti-TPO, anti-TG in relation to the fertile group. Similar to our result, a study conducted by Chen et al. showed a higher rate of positive TPO-Ab is females with UEI [16]. A meta-analysis pooling 4 studies showed that the presence of thyroid antibodies, anti-TPO, anti-TG in with unexplained subfertility (OR 1.5, 95\% CI 1.1e2.0) [17]. A study by Jatzko et al., showed high anti-TPO-Ab and TG-Ab levels were associated with failure of in-vitro fertilization process [18]. Similar results confirmed by Deroux et al. they observed that thyroiditis could be a cause of infertility; even in the euthyroid state, the presence of anti-thyroperoxidase antibodies and/or thyroglobulin is related to infertility [19].

$\mathrm{T}$ helper cells cytokines contribute to fertility and the success of pregnancy. Th1 cells produce inflammatory cytokines, such as interferon (IFN)- $\gamma$ to promote cell-mediated immunity. On the other hand, Th2 cells are involved in the humoral immunity by producing interleukin (IL)-4, IL-5, and IL-13. The Th1/Th2 balance has been used as a framework for predicting pregnancy outcomes. Several studies have confirmed that successful pregnancy is associated with a predominant Th2-type immunity, while Th1-type immunity is associated with pregnancy-related disorders [1].

According to our results, women with UEI showed statistically significant increases in the levels of serum IFN- $\gamma$, IFN- $\gamma$ mRNA when compared to the fertile group. To our knowledge, this is the first study investigating the circulating serum and expression levels of IFN- $\gamma$ in Egyptian women with HT and its possible associations with clinical and laboratory characteristics of UEI as well as thyroid disease.

Similar results were described in Mahdi observed that women with a reproductive failure have a significant increase in serum levels of IFN- gamma [20]. Also, Reid et al. confirmed higher levels of IFN-gamma in infertile females [21].

We investigated our results by ROC test to assess the power of serum IFN- $\gamma$ and IFN- $\gamma$ gene expression in the diagnosis of UEI among women with HT.

Regarding the power of serum IFN- $\gamma$ in differentiating fertile women from women with UEI, the AUC was 0.984 , a cutoff values of $16.7 \mathrm{mg} / \mathrm{dl}$ had sensitivity $=99.6 \%$, and specificity $=96 \%$; Concerning the power of IFN- $\gamma$ gene expression in differentiating fertile women from women with UEF, the AUC was $0.912(95 \%$ CI $=0.860-0.965)$ with sensitivity $=90.4 \%$, specificity $=94.2 \%$, and the cutoff values $2.65 \mathrm{mg} / \mathrm{dl}$. Regarding the power of the combination of circulating serum IFN- $\gamma$ and IFN- $\gamma$ gene expression for differentiating UEI from fertile women, the AUC was $0.953(95 \% \mathrm{CI}=0.889-1.000)$ with sensitivity $=90.4 \%$, specificity $=$ $94.2 \%$. To our knowledge, this is the first study to include the trial of estimating serum IFN- $\gamma$ and IFN- $\gamma$ gene expression as diagnostic signatures of unexplained infertility in women with Hashimoto's Thyroiditis.

Conclusion : $37.5 \%$ of the studied Egyptian women with HT had UEI there were statistically significant increases of the age of menarche, TSH, anti-TPO, anti-TG, serum IFN- $\gamma$, IFN- $\gamma$ mRNA in UEI group as compared to the fertile group. Cutoff values of $16.7 \mathrm{pg} / \mathrm{dl}$ for IFN- $\gamma$ and $2.65 \mathrm{pg} / \mathrm{dl}$ for IFN- $\gamma$ gene expression are specific and sensitive for differentiating UEI from fertile women.

\section{Declarations}




\section{Ethics approval and consent to participate}

Written informed consent was taken from all of the participants. The ethical committee of Faculties of Medicine, of Zagazig, University approved this study. The reference number is not applicable.

Acknowledgements : Not applicable.

Competing interests: The authors declare that they have no competing interests

Funding: No fund

\section{References}

1. Azad M, Keshtgar S, Jahromi BN, Kanannejad Z, Gharesi-Fard B. T helper cell subsets and related cytokines in infertile women undergoing in vitro fertilization before and after seminal plasma exposure. Clin Exp Reprod Med 2017;44(4):214-23.

2. Busnelli A, Paffoni A, Fedele L, Somigliana E. Impact of thyroid autoimmunity on IVF/ICSI outcome: a systematic review and meta-analysis. Hum Reprod Update 2016;22(6):793- 94.

3. Ehsani M, Mohammadnia-Afrouzi M, Mirzakhani M, Esmaeilzadeh S, Shahbazi M. Female Unexplained Infertility: A Disease with Imbalanced Adaptive Immunity. J Hum Reprod Sci 2019;12(4): 274- 82.

4. Forges T, Monnier-Barbarino P, Faure GC, Béné MC. Autoimmunity and antigenic targets in ovarian pathology. Hum Reprod Update2004;10(2):163-75.

5. Muller V, Ob'edkova K, Krikheli I et al. Successful pregnancy outcome in women with recurrent IVF failure and anti-hCG autoimmunity: a report of three cases. Case Reports in Immunology 2016;1:1-5.

6. Unuane D, Velkeniers B. Impact of thyroid disease on fertility and assisted conception. Best Pract Res Clin Endocrinol Metab . https://doi.org/10.1016/j.beem.2020.101378

7. Tomas T, Sreedharan S, Khadilkar UN et al. Clinical, biochemical \& cytomorphologic study on hashimoto's thyroiditis. Indian J Med Res 2014;140:729- 35.

8. Bossowski A, Harasymczuk J, Moniuszko A, Bossowska A, Hilczer M, Ratomski K. Cytometric evaluation of intracellular IFN-g and IL-4 levels in thyroid follicular cells from patients with autoimmune thyroid diseases. J Thyroid Res . 2011;4:13

9. The Practice Committee of the American Society for Reproductive Medicine, authors. Optimal evaluation of the infertile female. Fertil Steril . 2006;86(5):S264-S7.

10. Templeton A. Infertility and the establishment of pregnancy-overview. Br Med Bull . 2000;56:577- 87.

11. Matsubayashi S, Kasuga Y, Sakatsume Y, Akasu F, Volpé R. Serum interferon gamma levels in autoimmune thyroid disease. Clin Invest Med . 1990;13(5):271-274.

12. Jokar AO, Fourman LT, Lee H, Mentzinger K, Fazeli PK. Higher TSH Levels Within the Normal Range Are Associated With Unexplained Infertility. J Clin Endocrinol Metab 2018;103(2):632- 9.

13. Feldthusen AD, Pedersen PL, Larsen J, Toft Kristensen T, Ellervik C, Kvetny J. Impaired fertility associated with subclinical hypothyroidism and thyroid autoimmunity: the Danish General Suburban Population Study. J Pregnancy 2015; 132718. DOI: 10.1155/2015/132718.

14. Abalovich M, Mitelberg L, Allami C, Gutierrez S, Alcaraz G, Otero P, Levalle O. Subclinical hypothyroidism and thyroid autoimmunity in women with infertility. Gynecol Endocrinol. 2007;23(5): 27983.

15. Poppe K, Glinoer D, Van Steirteghem A, et al. Thyroid dysfunction and autoimmunity in infertile women. Thyroid 2002;12:997e1001.

16. Chen CW, Huang YL, Huang RL, Tzeng CR, Chen CH. Idiopathic low ovarian reserve is associated with more frequent positive thyroid peroxidase antibodies. Thyroid 2017;27:1194-200.

17. Van den Boogaard E, Vissenberg R, Land J, et al. Significance of (sub)clinical thyroid dysfunction and thyroid autoimmunity before conception and in early pregnancy: a systematic review. Hum Reprod Update 2011;17:605e19.

18. Jatzko B, Vytiska-Bistorfer E, Pawlik A, Promberger R, Mayerhofer K, Ott J. The impact of thyroid function on intrauterine insemination outcome-a retrospective analysis. Reprod Biol Endocri- 
nol2014;12:28.

19. Deroux A, Dumestre-Perard C, Dunand-Faure C, Bouillet L, Hoffmann P. Female infertility and serum auto-antibodies: A systematic review. Clin Rev Allergy Immunol 2017;53:78-86.

20. Mahdi BM. Role of some cytokines on reproduction. Middle East Fertil Soc J 2011;16(3): 220-3.

21. Reid JG, Simpson NA, Walker RG, et al. The carriage of pro-inflammatory cytokine gene polymorphisms in recurrent pregnancy loss. Am J Reprod Immunol 2001 (45):35-40.

$\backslash$

Table1: Clinical and laboratory characteristics of women included in the study.

\begin{tabular}{|c|c|c|c|}
\hline Parameters & Fertile group $(n=75)$ & $\begin{array}{l}\text { Group with unexplained } \\
\text { infertility }(n=45)\end{array}$ & $\mathrm{P}$ value \\
\hline age & $26.23 \pm 9.6$ & $29 \pm 10.46$ & 0.056 \\
\hline Age of menarche & $12.2 \pm 2.6$ & $13.2 \pm 1.9$ & $¡ 0.001^{*}$ \\
\hline Duration of infertility & - & $8.4 \pm 1.9$ & - \\
\hline TG (mg/dl) & $148.78 \pm 2.15$ & $150.8 \pm 3.97$ & 0.379 \\
\hline FT3 $(\mathrm{pg} / \mathrm{ml})$ & $2.32 \pm 0.25$ & $1.41 \pm 0.2416$ & ¡0.001* \\
\hline FT4(ng/dl) & $1.42 \pm 0.21$ & $0.52 \pm 0.25$ & ¡0.001* \\
\hline $\mathrm{TSH}(\mu \mathrm{IU} / \mathrm{ml})$ & $7.48 \pm 2.82$ & $9.57 \pm 3.01$ & $¡ 0.001^{*}$ \\
\hline Anti $\mathrm{TPO}(\mathrm{IU} / \mathrm{ml})$ & $235.2 \pm 38.2$ & $342.4 \pm 56.4$ & ¡0.001* \\
\hline Anti TG (IU/ml) & $3.2 \pm 0.6$ & $5.63 \pm 0.28$ & ¡0.001* \\
\hline Estradiol (pg/ml) & $35.6 \pm 5.7$ & $36.23 \pm 5.1$ & 0.800 \\
\hline Progesterone (ng/ml) & $0.86 \pm 0.09$ & $0.87 \pm 0.07$ & 0.831 \\
\hline Prolactin $(\mathrm{ng} / \mathrm{mL})$ & $9.63 \pm 1.4$ & $9.94 \pm 1.2$ & 0.239 \\
\hline $\mathrm{AFC}$ & $7.8 \pm 1.6$ & $8.1 \pm 1.6$ & 0.238 \\
\hline FSH (mIU/mL) & $7.6 \pm 1.46$ & $7.9 \pm 1.2$ & 0.237 \\
\hline $\mathrm{LH}(\mathrm{mIU} / \mathrm{ml})$ & $9.2 \pm 1.6$ & $9.4 \pm 1.2$ & 0.157 \\
\hline $\mathrm{AMH}(\mathrm{ng} / \mathrm{mL})$ & $1.4 \pm 0.16$ & $0.89 \pm 0.16$ & ¡0.001* \\
\hline IFN- $\gamma(\mathrm{pg} / \mathrm{mL})$ & $22.04 \pm 6.6$ & $33.9 \pm 8.6$ & ¡0.001* \\
\hline IFN- $\gamma$ mRNA & $2.4 \pm 0.46$ & $4.02 \pm 0.56$ & ¡0.001* \\
\hline
\end{tabular}

TSH: Thyroid stimulating hormone; FT3: Free triidothyronine. FT4:free thyroxine; Anti TG: Anti thyroglobulin antibodies; anti-TPO: anti-thyroid peroxidase antibodies; AFC: antral follicle cells; HT: Hashimoto thyroiditis. ${ }^{*} \mathrm{P}<0.05$ 


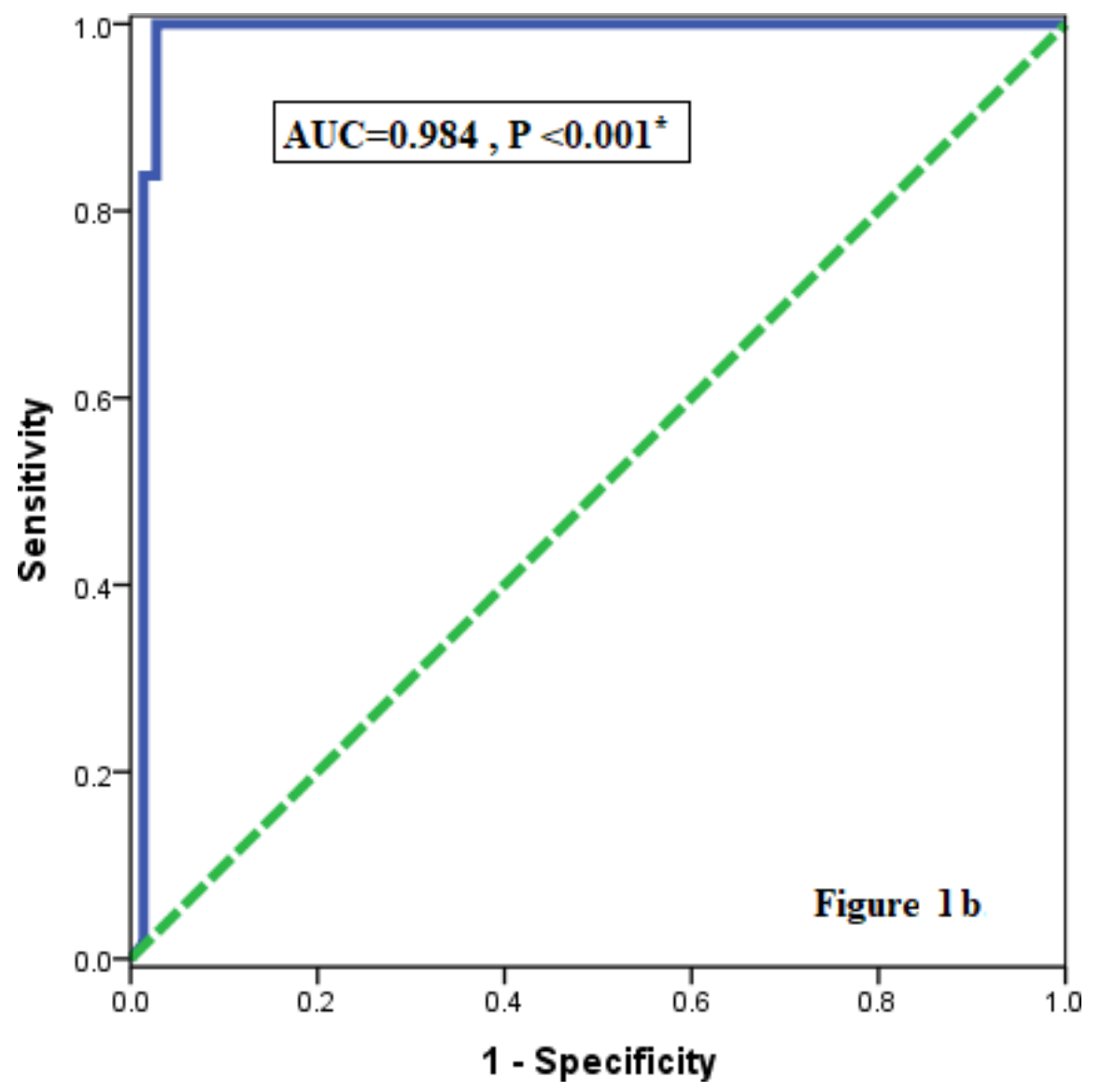

Fig.1: Receiver operating characteristic (ROC) curve of serum IFN- $\gamma(\mathrm{pg} / \mathrm{mL})$ for differentiating UEI from fertile women . 


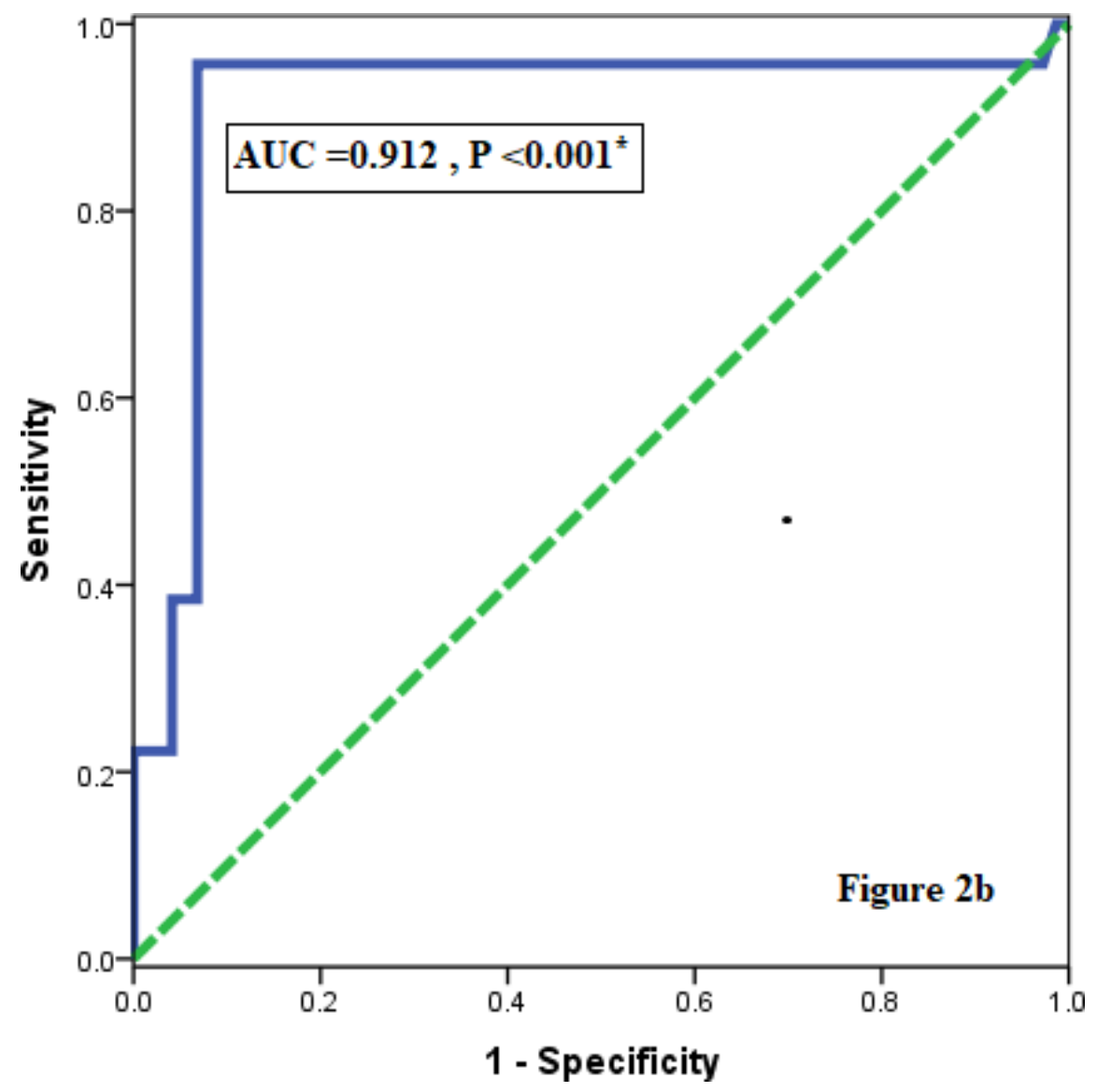

Fig.2: Receiver operating characteristic (ROC) curve of circulating IFN- $\gamma$ gene expression for differentiating UEI from fertile women. 


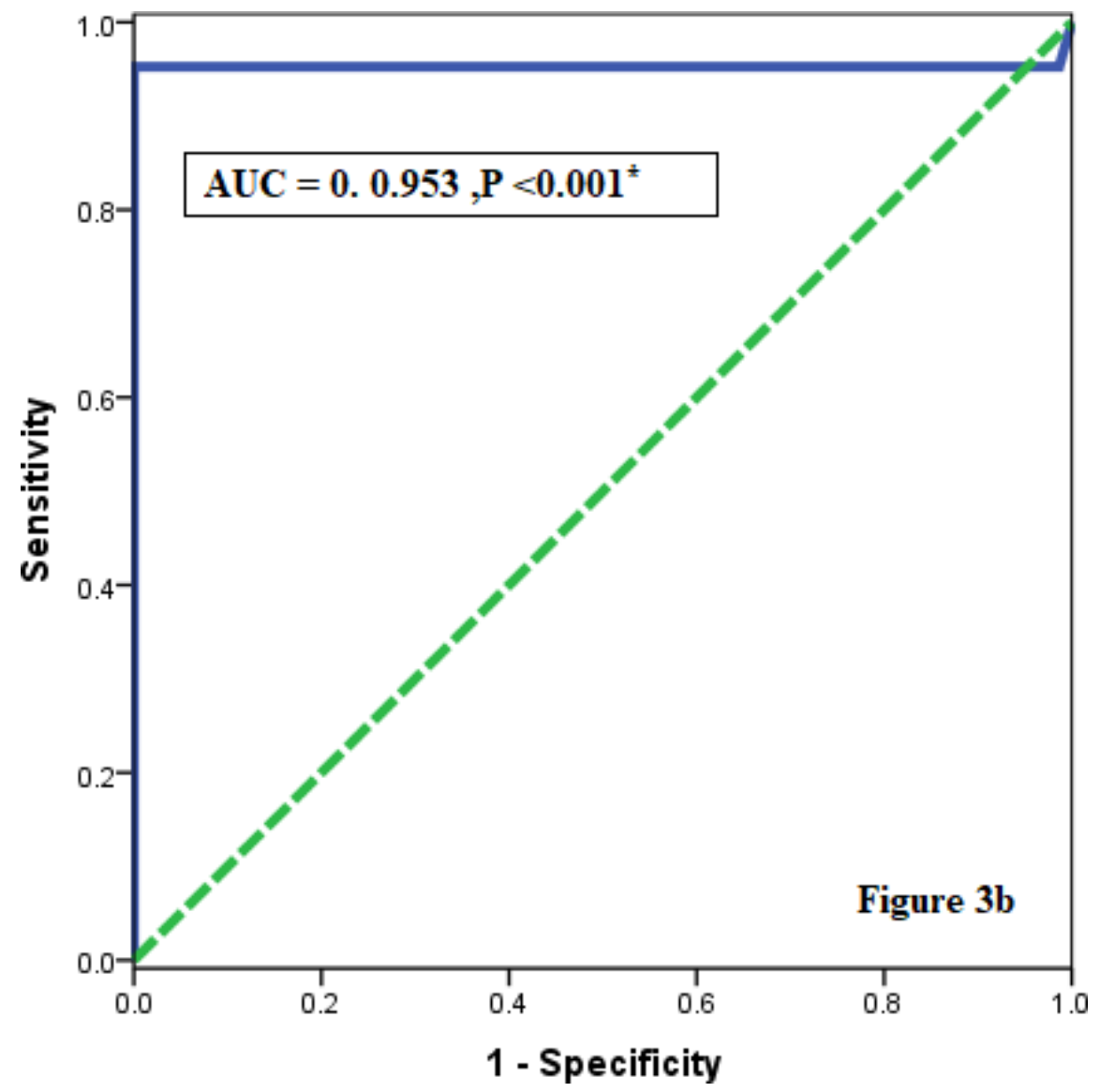

Fig.3: Receiver operating characteristic (ROC) curve of combination of circulating serum IFN- $\gamma$ and IFN$\gamma$ gene expression for differentiating UEI from fertile women. 